\title{
Simulated Breathing: Application of Molecular Dynamics Simulations to Pulmonary Lung Surfactant
}

\author{
Maksymilian Dziura ${ }^{1}$, Basel Mansour ${ }^{1}$, Mitchell DiPasquale ${ }^{1}\left(\mathbb{D}\right.$, P. Charukeshi Chandrasekera $^{1,2}$, \\ James W. Gauld ${ }^{1}$ (D) and Drew Marquardt $1,3, *$ (D) \\ 1 Department of Chemistry and Biochemistry, University of Windsor, 401 Sunset Ave, \\ Windsor, ON N9B 3P4, Canada; dziura@uwindsor.ca (M.D.); manso11h@uwindsor.ca (B.M.); \\ dipasqum@uwindsor.ca (M.D.); cpchandr@uwindsor.ca (P.C.C.); gauld@uwindsor.ca (J.W.G.) \\ 2 Canadian Centre for Alternatives to Animal Methods, University of Windsor, 401 Sunset Ave, \\ Windsor, ON N9B 3P4, Canada \\ 3 Department of Physics, University of Windsor, 401 Sunset Ave, Windsor, ON N9B 3P4, Canada \\ * Correspondence: drew.marquardt@uwindsor.ca
}

Citation: Dziura, M.; Mansour, B.; DiPasquale, M.; Chandrasekera, P.C.; Gauld, J.W.; Marquardt, D. Simulated Breathing: Application of Molecular Dynamics Simulations to Pulmonary Lung Surfactant. Symmetry 2021, 13, 1259. https://doi.org/10.3390/ sym 13071259

Academic Editor: Enrico Bodo

Received: 6 May 2021

Accepted: 5 July 2021

Published: 14 July 2021

Publisher's Note: MDPI stays neutral with regard to jurisdictional claims in published maps and institutional affiliations.

Copyright: (C) 2021 by the authors. Licensee MDPI, Basel, Switzerland. This article is an open access article distributed under the terms and conditions of the Creative Commons Attribution (CC BY) license (https:// creativecommons.org/licenses/by/ $4.0 /)$.

\begin{abstract}
In this review, we delve into the topic of the pulmonary surfactant (PS) system, which is present in the respiratory system. The total composition of the PS has been presented and explored, from the types of cells involved in its synthesis and secretion, down to the specific building blocks used, such as the various lipid and protein components. The lipid and protein composition varies across species and between individuals, but ultimately produces a PS monolayer with the same role. As such, the composition has been investigated for the ways in which it imposes function and confers peculiar biophysical characteristics to the system as a whole. Moreover, a couple of theories/models that are associated with the functions of PS have been addressed. Finally, molecular dynamic (MD) simulations of pulmonary surfactant have been emphasized to not only showcase various group's findings, but also to demonstrate the validity and importance that MD simulations can have in future research exploring the PS monolayer system.
\end{abstract}

Keywords: pulmonary surfactant; surface tension; adsorption; phospholipids; proteins; monolayer; respiration; air-liquid interface; squeeze-out; molecular dynamics

\section{Introduction}

Often unheralded, lipids play an integral role in many aspects of life, specifically in physiology. For example, they make up the enclosing bilayers of cells, separating the internal content from the exterior environment and making possible the countless reactions that define life. However, not all lipid structures come in the form of a bilayer. Nature offers countless examples of physiologically active lipid monolayers that are key to biological functions such as lipid circulation and respiration. In fact, perhaps the most crucial physiological monolayers is pulmonary surfactant.

Pulmonary surfactant (PS) is a critical lipid-protein complex within the respiratory system [1]. It is involved in many different functions, such as increasing lung compliance, preventing alveolar collapse, and even as an initial immunological defense. PS is secreted in the alveoli and lines the luminal alveolar surface, the primary site of gas exchange within the human lungs in the respiratory system [2,3].

Alveoli are formed by two types of surface epithelial cells, also referred to as pneumocytes. Type I pneumocytes make up most of the alveolar structure, constituting the alveolar wall, while Type II pneumocytes are secretory in nature: producing and secreting pulmonary surfactant $[4,5]$. The Type II epithelial cells create all the necessary components of the PS, followed by packaging and storage as lamellar bodies (LB) until ready for use $[4,6]$. Exocytosis of the LB from the Type II cells is followed by unravelling of lamellae into multilayer tubular networks called tubular myelin, which can be used to create a 
functional surfactant film or provide necessary lipid building blocks for an already preexisting layer [6,7]. The variable incorporation of tubular myelin lipids into a pre-existing PS monolayer likely further adds asymmetry to an already highly randomized and variable distribution of PS components. The film is a monolayer system in the alveolar cavity that forms an air-liquid interface, with the hydrophobic fatty acid tails facing the air, and the hydrophilic heads with an orientation towards the aqueous subphase. This system can be visualized in Figure 1.

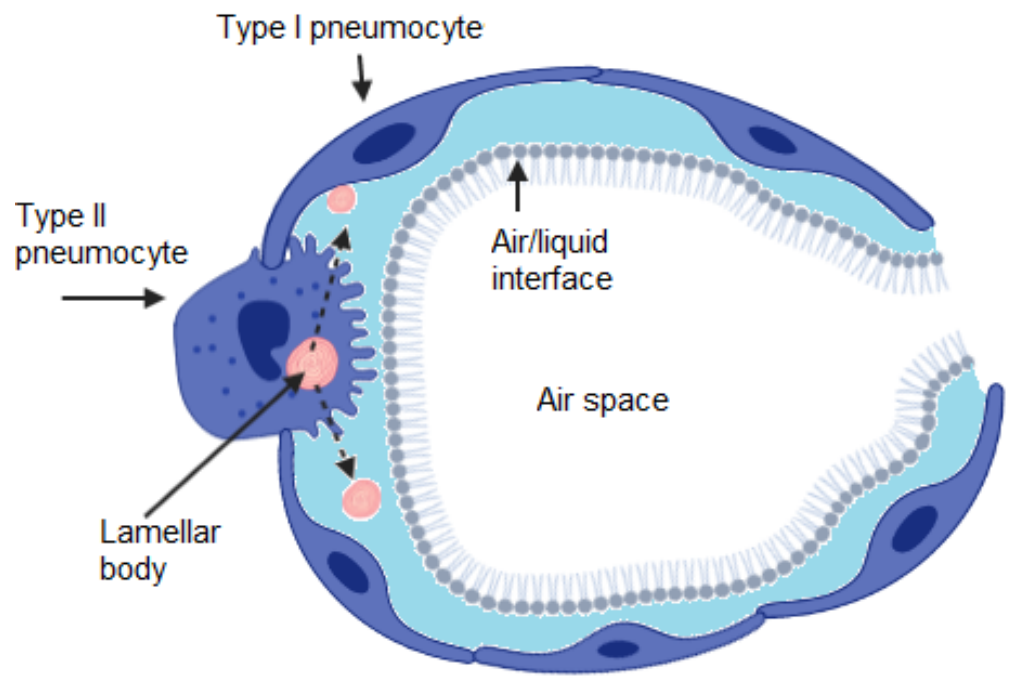

Figure 1. Schematic of the pulmonary surfactant system in the setting of an alveolus. The pulmonary surfactant lipid monolayer (grey) is maintained at the air-liquid interface by the action of Type II pneumocytes. Figure recreated from Hawgood et al. [8].

\section{Surfactant Composition}

The majority, almost $80-90 \%$, of pulmonary surfactant is made up of different types of lipids, with the rest of the composition mainly being the surfactant proteins (SP) SP-A, SP-B, SP-C, and SP-D [4,9]. This overall compliment of biomolecules gives PS a delicate balance of biophysical properties that allows it to function and play such a vital role in our everyday lives. The most notable properties exhibited are rapid adsorption to the air-liquid interface, efficient compression (during expiration) and expansion (during inhalation) of the film during a breathing cycle, as well as immunological protection $[2,10]$.

The lipid composition can slightly vary between individuals; however, pulmonary surfactant is mainly composed of phosphatidylcholines (PC) and phosphatidylglycerols (PG) [1,11] with trace amounts of phosphatidylethanolamine (PE), phosphatidylinositol (PI), phosphatidylserine (PS) and sphingomyelin (SM) [11,12]. Although the exact compositions of PS in mammals are typically dynamic and vary, an overall trend can still be seen in most PS systems. Remarkably, the individualized composition forms biophysically symmetric monolayers across individuals and even species. Table 1 offers a summary of the relative amounts of lipids present in the pulmonary surfactant. Cholesterol, a neutral sterol-type lipid, is also present at approximately $5-10 \%$ of the total lipid composition [13]. Though it has been theorized that cholesterol's original purpose in "air breathers" was to serve as an antioxidant [14], it has evidently evolved a more expansive function. This overall molecular composition helps PS to perform its main tasks of preventing lung collapse and stabilizing alveoli, largely through reducing surface tension at the air-liquid interface.

Lipids, containing a polar head and non-polar tails, are amphipathic and thus able to form films in alveoli at the air-liquid interface [10]. Dipalmitoylphosphatidylcholine (DPPC), a saturated lipid component that is the most abundant species in PS, helps the film in reducing surface tension to near-zero values [15]. This is likely because the two saturated chains permit tight lateral packing of the monolayer, which can reach the aforementioned low surface tensions without collapsing [16,17]. 
However, this saturated component alone would not be able to form a functional PS film. The film requires an unsaturated component, such as 1-palmitoyl-2-oleoyl-snglycero-3-phosphoglycerol (POPG), which lends fluidity to the film [10,18]. A combination of saturated and unsaturated lipids are necessary for a properly functioning PS. As already stated, DPPC allows for low surface tensions upon compression; however, overcompression of the monolayer can lead to some DPPC being displaced from the interface, affecting the ability of the film to respread [16].

Other acidic phospholipids have also been shown to have a role in increasing the efficacy of PS, specifically PG, and particularly in the process of adsorption [19,20]. Fluorescence studies have shown that SP-B can interact with PG, improving its biophysical activity compared to a system lacking SP-B [21]. The interaction leads to a more ordered lipid organization, which could attribute more efficiency, yet further work in the area is necessary. Healthwise, many acute respiratory distress syndrome (ARDS) patients have shown lower than normal amounts of PG in their PS, further cementing its importance in the biophysical and physiological properties of PS [16].

Table 1. Average Lipid Proportions in Pulmonary Surfactant. Note: $0 \%$ does not indicate an absence of lipid, but rather a presence in trace amounts $[5,22,23]$.

\begin{tabular}{cr}
\hline \multicolumn{1}{c}{ Lipid } & Relative Lipid Content \\
\hline Phosphatidylcholine (PC) & $70-85 \%$ \\
DPPC & $(\approx 40-55 \%)$ \\
Palmitoyl-myristoyl PC & $(\approx 9-12 \%)$ \\
Palmitoyl-palmitoleoyl PC & $(\approx 8 \%)$ \\
Palmitoyl-oleoyl PC & $(\approx 10 \%)$ \\
Palmitoyl-linoleoyl PC & $(\approx 6 \%)$ \\
\hline Phosphatidylglycerol (PG) & $5-10 \%$ \\
\hline Phosphatidylethanolamine (PE) & $0-5 \%$ \\
\hline Phosphatidylinositol (PI) & $0-3 \%$ \\
\hline Cholesterol & $5-10 \%$ \\
\hline
\end{tabular}

\subsection{Cholesterol}

Although cholesterol is not the majority constituent of PS, it does have a vital purpose in the monolayer system. One property the neutral lipid bestows is the ability to aid in lowering the phase transition temperature of lipids, which affects the physical state of the present milieu [24]. The transition temperature is the temperature where lipids shift from a rigid-solid gel phase into a more fluid liquid phase, or vice versa. Through lowering the transition temperature of the lipid monolayer, PS can exist in a fluid state over a broader temperature range and at a transition temperature lower than physiological [25].

Uniquely, cholesterol has been shown to have a differing effect on lipids depending on whether they are above or below the aforementioned transition temperature. If the lipid is above the transition temperature (fluid), cholesterol molecules pack themselves with the fatty acid chains, increasing van der Waals forces, and giving an overall condensing effect [25]. In contrast, if below the transition temperature (gel), the addition of cholesterol has seemingly the opposite effect, as van der Waals forces are decreased between adjacent fatty acids, giving the membrane more fluidity [26].

Cholesterol has also been shown to play a role in adsorption of DPPC films during the respreading and adsorption process. Results show that in two systems (DPPC/SP-B and DPPC/SP-C), the addition of cholesterol was detrimental to the processes [27]. Interestingly, the effects were counteracted when the protein concentration increased, although to levels above that seen in natural PS.

Regardless, there are other significant aspects to cholesterol. It allows for a greater inclusion of proteins, specifically SP-C within the monolayer, leading to a greater fraction 
of protein remaining in the system at a low surface tension of $0 \mathrm{mN} / \mathrm{m}$, whereas in a similar system missing cholesterol SP-C would be excluded from the interface at roughly $20 \mathrm{mN} / \mathrm{m}$ [27].

Additional studies indication that cholesterol's effect on surface viscosity is paramount to respiration $[25,28]$. Findings showed that even at a 1 mole percent addition of cholesterol there was a 6 -fold decrease on the viscosity of the monolayer, therefore giving rise to a theory connecting spreadability to cholesterol content. As Orgeig and Daniels stated, the surface viscosity should be high enough to withstand high surface tension and prevent surfactant from leaving alveoli, while on the other hand low enough to respread after compression is complete [25].

\subsection{Surfactant Proteins}

Pulmonary surfactant contains four different types of surfactant proteins (SP): SPA, SP-B, SP-C, and SP-D. SP-A and SP-D being hydrophilic and SP-B and SP-C being hydrophobic. The proteins are briefly outlined in Table 2 .

Table 2. Structural and Functional Characteristics of the Four Surfactant Proteins [8,23,29-45].

\begin{tabular}{|c|c|c|c|c|c|}
\hline Protein & Size (kDa) & Formations & Nature & Possible Interactions & Primary Functions \\
\hline SP-A & $32-38$ & $\begin{array}{l}\text { monomer } \\
\text { trimer } \\
\text { octadecameric complex }\end{array}$ & hydrophilic & $\begin{array}{l}\text { SP-B, SP-B/PG, DPPC, } \\
\text { Cholesterol, } \\
\text { Phospholipase A2 }\end{array}$ & $\begin{array}{l}\text { innate immune activation, } \\
\text { structuring tubular myelin, } \\
\text { enables lipid spreading, } \\
\text { homeostasis of lipid recycling }\end{array}$ \\
\hline SP-B & 8.7 & $\begin{array}{l}\text { oligomerize into } \\
\text { ring-shaped channels }\end{array}$ & hydrophobic & $\begin{array}{l}\text { SP-B, SP-C, PG, } \\
\text { cholesterol }\end{array}$ & $\begin{array}{l}\text { supports stability of lipids, } \\
\text { enhance respreading capabilities }\end{array}$ \\
\hline SP-C & $3.7-4$ & $\begin{array}{l}\text { oligomerize into } \\
\text { supramolecular complexes }\end{array}$ & hydrophobic & PG, Cholesterol & supports stability of lipids \\
\hline SP-D & 43 & $\begin{array}{l}\text { monomer } \\
\text { trimer } \\
\text { hexamer } \\
\text { X-shaped dodecamer }\end{array}$ & hydrophilic & $\begin{array}{l}\text { PI } \\
\text { G-protein-coupled } \\
\text { receptor } 116\end{array}$ & $\begin{array}{l}\text { innate immune activation, } \\
\text { support type } 2 \text { pneumocytes }\end{array}$ \\
\hline
\end{tabular}

\subsubsection{Hydrophilic Proteins}

SP-A is the most abundant protein in the PS system, which plays an immunological role, and exists as two isoforms SP-A1 and SP-A2 [4,46,47]. Overall, SP-A is part of the protein family known as the collectins, which are characterized by an $\mathrm{N}$-terminal collagenlike region, as well as a lectin domain in the C-terminus [48]. This type of protein is known for having immunological behavior. SP-A can act as an opsinin, binding to specific carbohydrates or lipid moieties of lung pathogens, therefore activating macrophages to undergo phagocytosis of the foreign microbes, such as bacteria, fungi, and viruses, leading to eventual clearance [4,46].This action is quite pivotal as PS is exposed to most inhaled contaminants. SP-A also factors in the biophysical properties, mainly through cooperating with proteins SP-B and SP-C in increasing surface adsorption [49].

SP-A is involved in the maintenance of Ps and surfactant homeostasis as a mediator of the formation of tubular myelin [49]. SP-A typically resides in the corners of the tubular myelin lattice, assisting in the adsorption of a functional film at the air-liquid interface [30]. SP-A knockout mice have been shown to be lacking tubular myelin networks, leading to a lower-density PS film [49]. Although some structural and functional differences were evident, the PS film was still able to function relatively normally. However, the mice did experience some drawbacks as they were more compromised by specific respiratory pathogens [49]. Another homeostatic role that SP-A actuates is binding to receptors of Type II pneumocytes to signal re-uptake and initiate lipid recycling. This action also inhibits secretion of further phospholipids, suggesting it acts as a regulator in a negative feedback loop [30,50]. 
This ability to contain both an immunological and biophysical function may have something to do with SP-A's isoforms. Regarding the two isoforms, SP-A1 and SP-A2, contain minimal sequential differences; however, studies show that the few amino acid difference may cause the contrasting functions. SP-A2 has been shown to be more biologically active in innate immunity than its counterpart, including greater resistance to certain bacterial infections such as Pseudomonas aeruginosa. One study showed that rats with higher amounts of SP-A2 stimulated a greater number of alveolar macrophages resulting in greater phagocytosis of the pathogen [47,51]. On the other hand, SP-A1 has been shown to contribute more biophysically than SP-A2, specifically in terms of efficient pulmonary surfactant reorganization [52]. Surfactant systems containing SP-A1 were able to achieve lower surface tension values in comparison to systems with SP-A2 or completely devoid of SP-A [52]. Thus, the ability to diversify function may be attributed to its complimentary isoforms.

SP-D, the other hydrophilic protein in the PS system, appears at almost 10-fold less the amount in comparison to SP-A [53]. The protein, also part of the collectin family, mainly exhibits a role in host defense. Although this protein appears at such low quantities comparatively, its deficiency can have serious adverse health effects. Studies done with SPD knockout mice, show survival after birth, but experience problems with cell morphology and pulmonary surfactant homeostasis, specifically in terms of hyperplasia of Type II pneumocytes, larger than usual intercellular lamellar bodies, and secretion of abnormally large amount of hydrogen peroxide from macrophages [46].

\subsubsection{Hydrophobic Proteins}

SP-B and SP-C, both of which begin as proproteins, are both hydrophobic in nature [54]. SP-B is modified into a smaller 79-amino acid lipid-associated peptide via proteolytic cleavage of the proprotein, while SP-C is cleaved into its mature form of 35 amino acids $[8,55,56]$. Both proteins play a significant role in the biophysical function of PS.

SP-B is perhaps the most critical surfactant protein, as it enhances the adsorption process of phospholipids to the film at the air-liquid interface, and aids the film in withstanding high surface pressures upon compression $[8,57]$. These functions could be because SP-B prefers to interact with anionic phospholipids, such as PG, which allowed for greater co-incorporation of PG to the interface along with SP-B. This is further supported by findings that SP-B knockout mice contain less PG in the monolayer film, leading to a less fluid and less functional film [57]. SP-B enhances the respreading capabilities after experiencing collapse during a breath cycle [8].

SP-C receives a lot of its functional ability from its structure, which is evident from its amino acid sequence that produces a tightly packed C-terminal alpha helix to anchor the interface-active N-terminal region. Interestingly, SP-C can exist with or without a palmitoyl modification. Work has shown that palmitoylation can promote respreading of DPPC/PG films over its non-palmitoylated counterpart [58]. The positive residues on the SP-C protein also help it in binding to the negatively charged phospholipids prior to insertion of its hydrophobic alpha helix [12].

Without a doubt, surfactant proteins contribute to the biophysical functions of surfactant, with the hydrophobic SP-B and SP-C at the forefront [54]. Both proteins act in a way that disrupts order in the lipid layer, which helps in processes such as the preferential exclusion of non-DPPC molecules [59].

Deficiency studies in mice demonstrate the relation of these two proteins to survival. Deficient SP-B mice died quickly after being born, compared to deficient SP-C mice that lived; though with a less stable surfactant $[60,61]$. Similar results were shown in young rabbits with induced frameshift mutation preventing production of SP-B [62]. SP-A knockout mice seem to live comparatively normal lives, whereas knockout SP-D mice do exhibit abnormal surfactant homeostasis and alveolar cell morphology [46]. 


\subsection{Surfactant Function}

As previously stated, the main function of PS is to coat the cavity of the lung's alveoli, forming the air-liquid interface to lower the surface tension and prevent collapsing of the alveoli (atelectasis). This single monolayer is vital to the respiration process. Through lowering the surface tension, the energy required to inflate the lungs during inhalation is decreased, which in turn boosts pulmonary compliance. Additionally, lower surface tension reduces the force of elastic recoil during inspiration, therefore preventing collapse of the alveoli. These seemingly paradoxical functions are a collective balance of properties emanating from its constituent lipids and proteins. Several theories have been conceived to understand the activity of the monolayer, and concurrently, molecular dynamics studies offer a valuable medium to decipher the intricacies of the system in its entirety.

Of the various properties that PS owns, conceivably the most important are its ability to rapidly adsorb, achieve near-zero surface tension, and specifically incorporate biomolecules into the film [63]. Rapid adsorption refers to PS being able to quickly form its functional film at the air-liquid interface in the respiratory system. Surfactant building blocks must diffuse near the air-liquid interface and spread at a relatively fast rate. This means that lipid vesicles, with the purpose of becoming a part of the PS film, must overcome an energy barrier to unravel and be introduced into the functional monolayer. Therefore, incorporation of fluid lipids would aid in this process, as the added fluidity can be thought to be synonymous to added mobility [63]. Addition of surfactant proteins offer greater electrostatic interactions and promotes reinsertion of lipids by stabilizing a "neck structure" to facilitate lipid diffusion. As illustrated in Figure 2, the neck structures are proposed to form with a multilayer reservoir during the compression-expansion cycles [63].

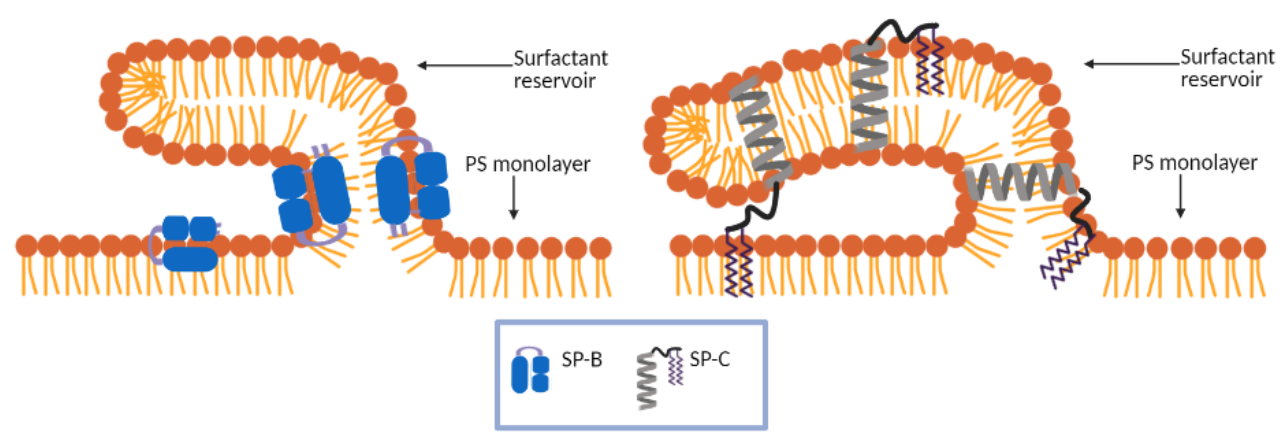

Figure 2. Representation of the squeeze-out and folding of the pulmonary surfactant monolayer into a multilayered surfactant reservoir during expiration-induced compression, including proteins SP-B and SP-C. Figure recreated from Zuo et al. [63].

Although fluid lipids play a large part in the rapid adsorption of the monolayer, its ability to achieve near-zero surface tensions relies heavily on the opposite, requiring more rigid lipids to form an order-condensed film [63]. It is particularly believed that saturated DPPC lipids are the main engine behind this biophysical property. Contradictorily, DPPC alone undergoes a very slow adsorption process, and a film with fluid lipids is not able to reach the low surface tensions of respiration. Therefore, this suggests that the interfacial system is highly dynamic and never concrete in its composition. Fluid lipids, and more importantly surfactant proteins, play a large role in adsorption at the air-liquid interface; however, fluid molecules impede the packing at low surface tensions and would be expelled from the interface as the alveoli compress. This is the basis of the to-be-discussed "squeezeout" hypothesis. The fluid molecules are expelled to a multilayer system associated with the interfacial film, which is largely under the control of surfactant proteins. Excluded lipids can be reintroduced to the interface as the monolayer expands.

\subsection{Role of Oxidative Stress}

One factor that greatly influences the function of PS is oxidative stress. Exposure to reactive oxygen species (ROS) in forms such as air pollution, ground level ozone, cigarette 
smoke, or byproducts of leukocytes and macrophages can be detrimental to the function of PS. For example, oxidation of unsaturated lipids and surfactant proteins can compromise the biophysical balance of the system and fuel severe pathogenesis [64]. Studies show that substituting oxidized version of lipids and proteins can alter surface activity, such as not achieving low surface tensions or affecting adsorption in comparison to a healthy PS system.

One group has quantified conjugated diene formation by exposing bovine lipid extract surfactant (BLES) to reactions producing ROS [64]. In comparison to a non-treated system, there was significant levels of conjugated dienes detected when exposed to hypochlorous acid or the Fenton reaction, two methods of inducing oxidative stress. After treatment, Rodríguez-Capote et al. quantified a decrease of approximately 20\% PC lipids and 40\% PG lipids, the two main components of PS [64]. The loss of unsaturated lipids, such as PG, could affect the biophysical activity of PS, as unsaturated lipids have an integral role in adsorption of PS [64]. In turn, this change could further lead to a lack of liquid-expanded (LE) phase in the PS film. Later investigations using isotherm data from a Langmuir trough demonstrate that when the oxidized lipid species Paze-PC (1-palmitoyl-2-azelaoyl-snglycero-3-phosphocholine) and Poxno-PC (1-palmitoyl-2-(9-oxo-nonanoyl)-sn-glycero-3phosphocholine) are introduced to DPPC monolayers, film compression results in ejection of oxidized lipids into the aqueous subphase, resulting in a loss of fluidity $[65,66]$.

The effect of ROS has also been observed on surfactant proteins. SP-B when extracted from the treated BLES samples, was shown to experience a structural change, as observed by a Western blot with a lower antibody affinity for the oxidized protein [64]. An ELISA test detecting protein carbonyl products of SP-B oxidation also confirmed that SP-B is prone to oxidation [64]. SP-C was also shown to be impaired by oxidative stress. In particular, oxidizing SP-C cleaves the thioester-linked palmitoyl group, reducing SP-C function, as previously discussed. Alternative oxidized SP-C behaviors are attributed to destabilizing modifications of amino acids [64]. Overall, the work identified oxidized surfactant proteins attribute a detrimental influence on the surface activity of PS. Interestingly, levels of native SP-B was able to recover some of the surface activity in oxidized SP-C samples, but the reciprocal results was no true. This further justifies the importance of SP-B in respiration [64].

\subsection{Proposed Mechanism of Function}

\subsubsection{Squeeze-Out Theory}

The primary theory that is used to describe functionality of pulmonary surfactant is the "squeeze-out" model. The basis of this model is that during compression of the surfactant film, molecules of greater fluidity must be expelled from the monolayer to decrease the surface area and stabilize the compressed state [67]. The unsaturated lipids expelled from the interface produces a saturated-rich monolayer and yields an asymmetric distribution of lipids across the PS system. This selective exclusion permits a greater proportion of the monolayer to be in a liquid-condensed (LC) phases enriched in DPPC, the main lipid responsible for achieving very low surface tensions. The selectivity of the lipids to be squeezed out is influenced by surfactant proteins. Since both SP-B and SP-C localize near fluid lipid domains, as seen in Figure 2, the proteins can help with the selection of fluid lipids to be squeezed out [67]. Studies have been able to lend a greater insight on the protein behaviors during this process. For example, SP-B promotes DPPC adsorption to the interface, and SP-C plays a greater role in the reinsertion of the displaced non-DPPC lipids [67]. Upon compression, SP-B is necessary for monolayer folding into a multilamellar surfactant reservoir, with these folds being reversible upon expansion, as they reincorporate into the film $[68,69]$. SP-C has been thought to play a large role in keeping the associated reservoirs close to the PS film. It has been suggested that during squeeze-out, the N-terminal palmitate groups of SP-C can remain anchored in the interfacial monolayer, while the transmembrane helical domain is expelled with a group of associated lipids, forming the multilayer reservoirs. This feature allows for a decrease in film surface area, as 
well as for the aforementioned multilayer reservoirs to remain closely associated with the film for reincorporation after compression. The squeeze-out ideally removes mainly fluid lipids with the goal of lowering the surface area of the surfactant film to reach near-zero values of surface tension.

\subsubsection{Supercompression Model}

The alternative model that has been proposed is called the supercompression model, where alveolar films behave as supercompressed fluid monolayers. The premise of this theory is that the surfactant film compresses at such a rapid rate that it transforms into an amorphous structure that is capable of withstanding significantly high surface pressure. This unique metastable state can fulfill the requirements to lower surface tension [70-72]. Supercompressed monolayers exhibit unorthodox behavior; rather than recoiling back to an equilibrium after compression, a supercompressed monolayer sustains a low surface tension well below equilibrium and therefore maintains its supercompressed qualities [70]. In phospholipid-only films, maintained supercompression of the surfactant film can prevent alveolar collapse, even if surface tension is above equilibrium [70]. It is important to note that the two previously mentioned schools of thought are not mutually exclusive. It is feasible to believe that a metastable supercompressed film may be able to form after some lipids are excluded into the associated reservoir.

\section{Molecular Dynamics}

Molecular dynamics (MD) simulations are of great impact on molecular biology and biochemistry, which has been emphasized in recent years [73]. These simulations "snapshot" the behavior of biomolecules, such as proteins, in full atomic detail and at a very fine temporal resolution [73]. Due to major improvements in simulation speed, accuracy, and accessibility, together with the proliferation of experimental structural data, the appeal of biomolecular simulations to experimentalists is of ever-growing interest. Simulations have proven valuable in a vast array of cases, such as predicting functional mechanisms and interactions of proteins and other biomolecules. This allows for revelations in areas such as the structural basis for various diseases, or in designing and optimizing novel small molecules and therapeutics [74-77].

MD is a simulation technique that has become more relevant and advantageous in the field of biomolecules. Simulations of individual and collections of molecules can enhance knowledge of countless biochemical systems, processes, or interactions through the computational analysis of their collective chemical and physical properties. In the case of PS, groups have examined diverse aspects of the monolayer. Studies approach the role of lipid composition, protein presence, and cholesterol abundance on the surface tension, pressure, and free energy of the surfactant system as a whole.

Based on a general model defined by the physics governing interatomic interactions, MD simulations can predict how every atom in a lipid system will behave over time. These simulations can capture a wide variety of important biomolecular processes and reveal the positions of all the atoms at femtosecond temporal resolution, including the conformational change of monolayers. Importantly, such simulations can also predict how biomolecules will respond - at an atomic level — to a defined perturbation. To name a few: the addition/removal of a ligand, a change in a system parameter such as bilayer thickness, the number of lipids per layer, or a temperature change. Fortunately, the basic idea behind MD and performing a simulation is quite straightforward. Given the positions of all the atoms in a biomolecular system (e.g., a lipid monolayer surrounded by water and vacuum, occasionally with a ligand), a researcher can calculate the force exerted on each atom by all the other atoms. One can thus use Newton's laws of motion to predict the spatial position of each atom as a function of time. In particular, by knowing information about the trajectory of an atom through time, a researcher can calculate the forces on other atoms, then-using those forces-the position and velocity of each atom in the system can be predicted. The resulting trajectory is in essence a three-dimensional movie that 
describes the atomic-level configuration of the system at every point during the simulated time interval.

Statistical learning techniques and docking methods for predicting monolayer and bilayer lipid properties cannot quantitatively estimate binding free energies, pressure, and surface tension [78]. Full atomistic molecular simulation methods are required, yet are understandably difficult for large systems considering the substantial computational cost. Alternatively, a system can be investigated using a coarse grain (CG) model, which considers the most important atoms within the system while neglecting others; for instance, hydrogen atoms. In a study published in November 2013, the free energy barrier calculated using molecular dynamics techniques for both full atomistic and CG models, showed that the values from the CG simulations are of similar accuracy as those from the full atomistic model, while achieving so with over a 500-fold decrease in computational demand [78]. The results also find that extensive sampling is extremely important to obtain accurate free energy barriers, which is only within reach for the CG models.

\section{Molecular Dynamics of Pulmonary Surfactant}

\subsection{Choosing Lipids to Build a Monolayer}

The primary building block of PS are lipids; therefore, many groups investigate the effects of varying lipid types on the biophysical properties of PS. Rose et al. focused on how the PS monolayer, such as pure DPPC or 7:3 DPPC/POPG systems, would react to a change in lipid composition and density [79]. It was observed that with a lipid density of 0.50 , $0.55,0.60,0.70$, and $0.80 \mathrm{~nm}^{2} /$ lipid, the headgroup-to-water interface was planar for all compositions of PS. However, two compositions, specifically 0.45 or $0.40 \mathrm{~nm}^{2} /$ lipid, started to exhibit deformations which varied depending on the lipid composition. Simulations further determined that the deformation mainly constituted a vertical movement of lipids beyond the plane, with no evidence of any lipid movement laterally [79]. One noteworthy observation was that DPPC monolayers would begin to buckle at $0.45 \mathrm{~nm}^{2} /$ lipid, and showed a bigger deformation at $0.40 \mathrm{~nm}^{2} /$ lipid. However, during this deformation no lipids exit the monolayer system. The tails of the DPPC lipids also exhibit a higher degree of ordering with increased lipid density. At these higher densities $\left(0.40\right.$ and $0.45 \mathrm{~nm}^{2} /$ lipid), it seemed that the deformation relieved orientational constraint on the chains during compression. In comparison to DPPC, pure POPG monolayers do not exhibit a planar structure until compressed to $0.40 \mathrm{~nm}^{2} /$ lipid, most likely due to the smaller head group size [79]. This fueled the simulation of 7:3 DPPC/POPG monolayers, which was planar at $0.45 \mathrm{~nm}^{2} /$ lipid, showing that this small amount of doping was able to influence a DPPCrich monolayer. This mixed system also showed a lower lipid chain order at $0.40 \mathrm{~nm}^{2} /$ lipid than at $0.45 \mathrm{~nm}^{2} /$ lipid, which gave the monolayer chains more conformational freedom and could explain the fluidity that PS can attain at low surface tensions [79]. Overall, this mixed composition is shown to be more similar to physiological state of PS, and may explain some of its behavior.

The DPPC/POPG system also showed evidence of some POPG molecules leaving into the aqueous layer at high lipid densities. This gives relevance for the previously mentioned, squeeze-out model, which causes the monolayer to become enriched in DPPC during the expiration process through selective squeeze-out of fluid lipids [79].

Although the simulations performed by Rose et al., prove to have some reassuring results to previous knowledge of PS, further simulations would need to be conducted for longer periods of time and on larger systems, as the initial studies are too limiting to exhibit large-scale phenomenon such as phase coexistence. Organization of lipids into distinct phases can factor into functionality, as well as the inclusion of proteins and cholesterol, which were omitted and could act as important variables to the system.

\subsection{Tuning the Phase Transition}

Lipid composition is a major factor for the biophysical characteristics of the PS, but composition complexity also dictates ordering and disordering in the PS system. One 
group, Duncan et al., looked at how this transition was altered by the various components of endogenous PS. Simulations were conducted by increasing or decreasing temperature, depending on whether the system started in an ordered liquid-condensed (LC) or disordered liquid-expanded (LE) state [80]. It was evident when the temperature was lowered that there was an emergence in a more ordered condensed phase, or LC phase [80]. The overall examination of the phase transition temperature, defined as the point of coexisting ordered and disordered phases, was further investigated to see how they were affected by addition of other molecules.

In a monolayer system of 1:1 DPPC/POPC, the addition of POPC, an unsaturated lipid led to fluidization of the monolayer while also decreasing the hysteresis loop. Counterproductively, a threshold was reached where the amount of POPC throughout the membrane was high enough to prevented DPPC from nucleating a condensed region. This occurs even at a temperature greater than where POPC can make a condensed phase, producing a system with a lower LC-LE transition temperature than true DPPC. Evidence shows a disordered monolayer persist at a temperature as low as $293 \mathrm{~K}$ [80]. Overall, the simulations demonstrated one of the purposes and caveats of unsaturated lipids in PS, that being adding capricious fluidity to the monolayer.

When cholesterol was added into the monolayer at physiological proportions, the transition temperature was reduced to $313 \mathrm{~K}$, where ordering would occur with the remaining LE phase. It was also evident that the cholesterol preferred to localize at the boundary interface of disordered and ordered lipids [80]. This behavior of cholesterol seems to be consistent regardless of amount of LE or LC phase present. The removal of cholesterol could have large consequences on the structure and spreading of PS, although, due to contradicting reports, there is a lot of uncertainty on how severe. Though it is thought that this behavior is largely affected by alternative variables, it is generally accepted that cholesterol plays a role in disordering the LC phase and ordering the LE phase, thus forming the more traditional liquid-ordered (Lo) and liquid-disordered (Ld) phases [80].

\subsection{Looking beyond the Interface}

Simulations have proven to be a valuable tool to probe the relationship between the physiological monolayer and the associated bilayer reservoir systems. For example, surface tension is a key modulator of monolayer stability. As lower and lower surface tensions are achieved, the monolayer approaches a threshold where it becomes unstable and presents signs of collapse [81]. The process of monolayer collapse is a prime example of an interaction between the monolayer and bilayer systems. Typically, induced bends or undulations in the monolayer prefaces the collapse of a section of the monolayer away from the interface and into the reservoir system [81,82]. Simulations have corroborated this process, showing lipid "leaving groups" moving from the interfacial monolayer to a reservoir in the hydrophilic subphase, rather than the air subphase $[81,83]$. This seemingly counter-intuitive action is justified considering that the direction of folding into the liquid subphase permits the hydrophilic headgroups to shelter the tails, reducing the free energy associated with exposing the hydrocarbon chains to air [81]. This recent example endorses the presence of a reservoir system where lipids may be intermittently accommodated away from, but still adjacent to, the interface.

\subsection{Supercompression through the In Silico Lens}

The supercompression model was briefly outlined to also be a possible explanation of the functionality of PS, specifically that if a film is rapidly compressed it can form an amorphous state that is able to withstand high surface pressures [70,81]. Unfortunately, simulations have trouble recreating supportive evidence of this theory as the length of the systems is significantly smaller than in an experimental or physiological setting. Baoukina et al. attempted to investigate this phenomenon; however, they found that during simulations the compression rate was not able to supersede the rate of collapse, and hence an amorphous state was not able to be visualized [84]. It is important to note that though the 
supercompression model could not be validated by simulation, this should currently be considered a computational limitation, rather than outright counterevidence.

\subsection{Adding Surfactant Proteins}

The inclusion of SP- $\mathrm{B}_{1-25}$ into a monolayer of DPPC demonstrates unique behavior. Simulations of the peptide-monolayer system showed an ordering transition at $303 \mathrm{~K}$. The peptide would bunch up in an LE domain, whereas away from the area localized by the protein, the monolayer would greatly exhibit LC phase qualities with little defects. The disordering transition was exhibited at 308K, showing mainly LE phase with minimal LC phase, this shows that as the area became more disordered, it comes at a loss of the ordered LC domain. Hysteresis, measured as a percentage of hexagonal packing versus temperature, was also studied by Duncan et al. In this case, the addition of the peptide eradicated the ordering transition, which can act as potential evidence that $\mathrm{SP}-\mathrm{B}_{1-25}$ nucleated disorder into the monolayer [80].

According to Duncan et al., the main function of the surfactant proteins is the influence they have on lipid packing. It is mostly seen that the proteins SP-B and SP-C tend to localize in the fluid phase on the membrane. According to several microscopy techniques there is evidence that SP-B effects the distribution of LE and LC in DPPC layers. This discovery led to the belief that SP-B may promote the creation of a nanoscopic framework of lipid and lipid-protein nano-domains [80]. According to the simulations done by Duncan et al., the protein prefers to reside in an LE phase domain and to cluster at domain boundaries [80].

Further simulations were executed with the introduction of a greater number of proteins at $303 \mathrm{~K}$. The system formed a large LC domain with several LE phase around the SP-B peptides. Here, the peptide acts as a defect within the monolayer. For the monolayer to become more ordered, it would need to propagate where peptide is absent. This process would force peptide-laden disordered areas to be driven towards other similar domains, and promote these disordered blocks to coalesce and cause protein aggregation [80]. Further simulations show how the position of the protein plays into these effects. Duncan et al. positioned SP-B peptides in a line, a square, and a cluster orientation. The line and square configuration require a greater overall surface area, therefore less LC phase was visualized as there was a greater distribution of LE phases phase to accommodate the protein. In contrast, with the cluster configuration the proteins were more condensed, allowing for more LC phase to exist and showing LC phase is more favorably formed when SP-B occupies minimal membrane surface area [80].

The other most common peptide found in PS is SP-C. Similar simulations were done where SP-C was inserted into initially ordered and disordered DPPC monolayers at initial temperatures of $303 \mathrm{~K}$ and $308 \mathrm{~K}$. At $308 \mathrm{~K}$, the disordered membrane remained disordered, and the ordered membrane stayed ordered, whereas in the SP- $\mathrm{B}_{1-25}$ system there would be disordering in the initially ordered monolayer [80]. It was also seen that the SP-C protein inserts itself deeper into the membrane. The SP-C systems also do not show as much deformation in the vicinity of the protein as compared to $\mathrm{SP}-\mathrm{B}_{1-25}$, where deformations can be visualized. These deformations can be seen to give membrane instability prior to possible collapse. Interestingly, SP-C palmitoyl chains seem to remain embedded in the monolayer even at high surface pressures, where it is believed the protein begins to squeeze-out, along with some of its associated lipids.

Simulations of SP-C suggests the importance of palmitoylation to the peptide. Other researchers have extended these studies on the effect of palmitoylation on SP-C. According to Johansson and Curstedt, SP-C loses much of its important functionality when it is not palmitoylated. This directly hinders adsorption/respreading, mechanical stability, and the surface tension lowering properties of the PS [85].

The addition of SP-B has a greater fluidizing effect than SP-C; however, SP-C does contain more hydrophobic character. Simulations have shown that SP-B has a decreasing effect on the order of local fatty acids in a PS monolayer, with this effect being progressively 
nullified for fatty acids further away from the peptide. This localized fluidization makes the monolayer more prone to collapse in these regions [80].

Recent simulations of SP-B oligomers, specifically the hexamer, have showed some interesting results regarding the movement of PS-involved lipids. The hexamer forms in a way that gives rise to a central pore, which is depicted in Figure 3. Simulations by Liekkinen et al. have shown that the central pore of the SP-B ring is able to perturb lipids, suggesting a new possible mechanism for lipid transfer [40]. This behavior leads the central cavity to fill with lipids regardless of monolayer composition. The effect of POPG was also investigated by the group, and was achieved by positioning the hexamer in the vicinity of the membrane in a parallel orientation. Simulations with different membrane compositions, such as one in the absence of POPG, were used as a control. Results showed that POPG has an influence on the adsorption, affinity, and orientation of the SP-B hexamer [40]. The binding process of a physiologically relevant mixture with POPG (versus one with no POPG) showed an increase in binding speed by approximately a factor of 4 [40]. There also seems to be more partial unbinding of protein dimers, of the hexamer, to the monolayer in the absence of POPG in the film. This is evidence of stronger electrostatic interactions of the SP-B in the presence of POPG. Additional simulations with the monolayer showed that the hexamer has high-affinity sites for both POPG and cholesterol, contrasting DPPC and POPC [40]. Notwithstanding, the affinity for the different lipids was found to be highly dependent on the overall composition of the membrane. As previously stated, the hexamer also promoted protrusions and perturbation in the monolayer, with the extent of which depended on the composition of the monolayer. In total, the group concludes that SP-B hexamers cause perturbation in the PS monolayer via the aforementioned central cavity.

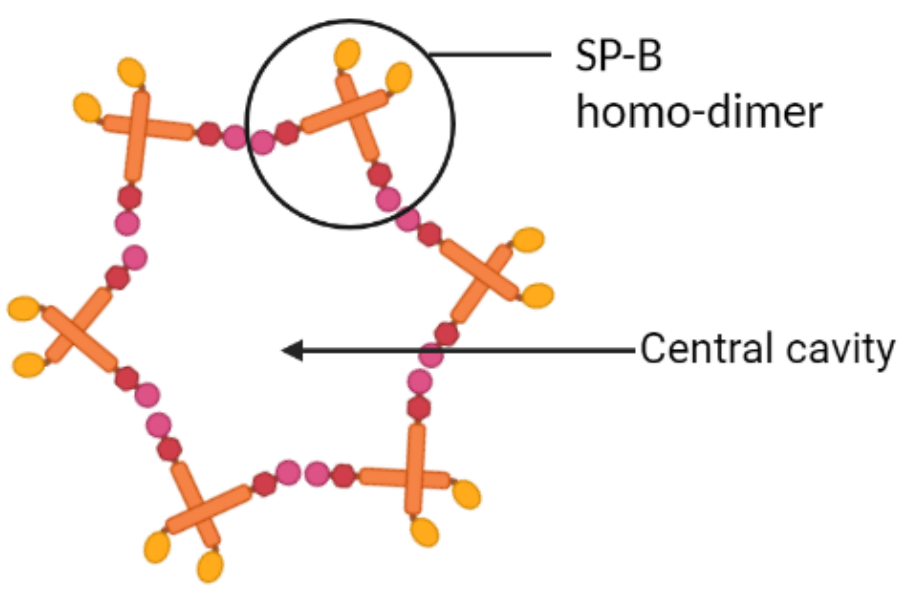

Figure 3. A simplified schematic of how SP-B homodimers can interact to create a hexameric structure. The structure can peripherally orient either parallel or perpdenicular to the lipid layer, depending on composition. In the parallel orientation all subunits are engaged in a lipid-protein interaction, while in the perpendicular orientation only a few are engaged [40]. This image was recreated from Liekkinen et al. [40].

There are also MD simulations that observe specific interactions rather than the complete PS system. Freites et al. investigated the relationship of SP-B, specifically the functional portion $\mathrm{SP}_{-} \mathrm{B}_{1-25}$, and how it interacts with anionic phospholipids. Simulations, where $20 \mathrm{wt} \%$ of the peptide was supplemented into a monolayer of palmitic acid (PA), were undergone to examine the interactions. Freites et al., performed the experiment at $289 \mathrm{~K}$, for the monolayer to be below its gas-liquid-tilted condense phase triple point. The addition of the peptide showed evidence causing the formation of a disordered phase, which was experimentally validated through fluorescent microscopy experiments [86,87]. Electron density profiles of the simulations were able to show that cationic residues on the peptide (Arg and Lys) were located all near the anionic phospholipid headgroups, showing that electrostatic interactions are likely similar to that of the protein seen in a DPPC/DPPG 
monolayer [88]. The electron density profile also showed that aromatic amino acids were positioned away from the hydrophilic aqueous region closer to the phospholipid tails. One final piece of information evident was that as the monolayer was more compressed, the $\alpha$-helical region was seen to lose some helical character, becoming more elongated and allowing the peptide more elongated, which allowed the peptide to stay in the monolayer as it compressed and decreased in volume [88]. Overall, the simulations highlighted electrostatic interactions seen between SP-B and anionic phospholipids.

\subsection{SP-D in Immunology}

Many groups focus on SP-B and SP-C in MD simulations as they have a great biophysical effects on the system, yet there are very few in silico studies investigating the hydrophilic immunological proteins. One protein with immunological effects, SP-D, was simulated to highlight its role in the body's immune system. SP-D shows interactions with N-linked glycans of hemagglutinin-an envelope protein of influenza A virus [89]. Hemagglutinin contains a sialic acid receptor which allows for viral entry via attachment to sialyated glycoproteins of host cells, and therefore virulence has been correlated with avoidance of SP-D. Simulations were able to show and make evident this interaction, as well as also show that the peptide inhibits the sialic acid binding site on the viral protein. Goh et al. ran simulations on two forms of SP-D, a wild-type and a gain-of-function double mutant, D325A + R343V. This allowed for comparison of the protein actions and the mechanism by which they may respond to and clear the virus [89]. Simulations studying the exposed surface area of the sialic acid binding site were done with they, where both peptides eventually cause full blockage of the site over the duration of the simulation. Although it was seen that both proteins block the sialic acid binding site, simulations indicated that the double mutant protein product interacted with a greater affinity, potentially attributed to greater hydrogen bonding and the presence of hydrophobic interactions that the WT does not exhibit [89]. Simulations also showed different spatial orientations of the WT and D325A + R343V peptides, which may have an impact on viral clearance [89]. This higher affinity and particular orientation could suggest that that the D325A + R343V strain can be further investigated for its greater potential for viral neutralization, for example Goh et al. suggests looking at other similar systems where hemagglutinin is in a close vicinity to the sialic acid binding site, such as in different strains of H1N1 [89]. Further research in this area is required.

This work by Goh et al. is a choice example to put into perspective the immense amount of knowledge that can be gained through simulation studies. Beyond a detailed perception of the biophysical aspects of the pulmonary surfactant system, computation yields a wealth of trajectories including the immunological effects of PS proteins and host defense interactions. Respiratory illnesses, such as influenza A virus subtype H1N1 or SARS-CoV-2, are modern examples of serious diseases where simulations, though perhaps not with PS, could potentially be of use to investigate viral interactions and inform more directed investigations into fundamental therapeutics.

\subsection{Impact of Foreign Nanoparticles}

One final area where simulations have been of considerable impact and interest is in inhaled nanoparticles (NPs), which may enter the PS monolayer and affect the system. The field of NPs is quite expansive, encompassing an array of classes which should be investigated and of interest to pulmonary physiology. A lot of focus is on toxic foreign pollutants, though in contrast NPs may be studied as possible drug delivery carriers [90]. In one example, insertion of less than $1 \mathrm{wt} \%$ gold nanoparticles into a PS mimic of DPPC/POPG/SP-B (70:30:1) showed that the gold NPs compromised the surface activity of PS [91]. The gold NPs devastated the ability of PS to both achieve low surface tensions and adsorb to the interface. Studies such as this can greatly be augmented by molecular dynamics studies to define the specific interactions driving failure of the PS by airborne particulates. 
Hydrophobicity or hydrophilicity of a NP is a major characteristic that can dictate the behavior of PS films when exposed to NPs. Yue et al. delved into this area using MD simulations. The group looked at the following range of NPs: hydrophilic $\mathrm{SiO}_{2}$ and $\mathrm{C}_{6} \mathrm{H}_{14} \mathrm{O}_{2}$, semi-hydrophilic $\mathrm{CaSO}_{4}$, and hydrophobic elemental carbon (C-NP). These NPs were particularly of interest due to their prevalence in exhaust emissions and wind-blown soil as routes of inhalation exposure. The two hydrophilic NPs were showed to have similar effects on the monolayer system (DPPC with added SP-B, SP-C and cholesterol) as both have comparable hydrophilic character. Both NPs were able to freely cross the monolayer system during inhalation/exhalation cycles and hence did not have a great impact on the biophysical function of PS. Rapid diffusion through the monolayer was due to the attractive forces of the hydrophilic head groups for the NP, as well as the attraction to the liquid phases across the monolayer. Simulations identified that these attractive forces are sufficiently strong to overcome the energy barrier, and thus permits minimal perturbation upon crossing [92]. $\mathrm{CaSO}_{4}$ was shown to have a minimal effect during the inhalation state; however, it was possible to become lodged in the monolayer during exhalation affecting the surface pressure. The NP with the greatest evident impact was that of the hydrophobic C-NP. C-NP was not able to cross the monolayer, but instead was adsorbed to the interface causing structural disturbances as it appeared to be enveloped by the monolayer, resulting in noticeable bulges protruding into the liquid subphase [92]. The hydrophobic nature of C-NPs embedded into the hydrophobic acyl chains of DPPC, affecting the overall ordering of the lipids. This perturbation in acyl chain packing prevents the film from attaining low surface tensions, which is the benchmark of functional surfactant.

As such an example, studies focusing on different foreign molecules' impacts on the PS can be greatly benefited using molecular dynamic studies. MD can provide atomistic-scale interactions that may be driving a macroscopic behavior in systems as complex as PS. As a platform, molecular dynamics can guide deeper investigation of potentially harmful NP pollutants to offer insight into the origin of respiratory disease states, and provide trajectories for anything from safer NP design to novel therapeutic approaches.

\subsection{Oxidative Stress Impact on PS Lipids}

Oxidative stress is one variable that can bring large variance and detrimental effects into a PS system. As previously mentioned, oxidation of lipids by ROS can lead to oxidized lipids such as Poxno-PC, which have a terminal $\mathrm{CHO}$ group on the $s n-2$ chain of the lipid [66]. Simulations investigating how Poxno-PC behaves and effects the PS monolayers have been completed. Initially looking at a simplified, DPPC:POPC (1:1) system, POPC molecules were replaced with Poxno-PC until a composition of DPPC:POPC:Poxno-PC (0.5:0.4:0.1) was achieved [66]. Stachowicz-Ku'snierz et al. investigated the effect through surface pressure isotherms, with a focus on the area per lipid range of 1.0, 0.9, 0.8, 0.7, 0.6, and $0.5 \mathrm{~nm}^{2} /$ lipid. At $1.0 \mathrm{~nm}^{2} /$ lipid and $0.9 \mathrm{~nm}^{2} /$ lipid behavior is similar. Both conditions start with the headgroup in the hydrophilic subphase, and the lipid tails directed in the opposite direction; however, in the case of the oxidized chain, it is seen that within the initial nanosecond the $\mathrm{CHO}$ group is attracted into the hydrophilic region of the system. The tails rarely extend back out over the course of the simulation [66]. The $0.8 \mathrm{~nm}^{2} /$ lipid condition is also similar, although with some thickening in the monolayer. Once compressed to $0.7 \mathrm{~nm}^{2} /$ lipid there is less $\mathrm{CHO}$ observed interacting with the hydrophilic phase, as more chain straightening is observed [66]. At $0.6 \mathrm{~nm}^{2} /$ lipid, the pressure begins to induce undulations in the monolayer and the $\mathrm{CHO}$ groups are no longer able to reach the hydrophilic region. The oxidized $s n-2$ chains are forced to an all-trans configuration enforcing that membrane order is increasing [66]. At $0.5 \mathrm{~nm}^{2} /$ lipid, the system experiences a metastable state with large undulations stabilized by lateral separation of DPPC into condensed troughs and POPC-rich crests [66]. All the Poxno-PC sn-2 chains are locked into the trans confirmation and does not enter the hydrophilic region, as this would lead to monolayer collapse. An important caveat, as simulations were conducted at a fixed volume, the system was not permitted to experience collapse [66]. Overall, these MD 
simulations compliment experimental data demonstrating that inclusion of oxidized lipid drives monolayer collapse at lower surface pressure and higher area per lipid compared to the non-oxidized system [66].

Further experiments have also been done with a lipid composition more comparable to natural PS. Olzy'nska et al. investigated a system of DPPC:POPC:POPG:cholesterol (0.50:0.25:0.15:0.1) using both experimental and simulation-based data [93]. With the replacement of $10 \%$ POPC by Poxno-PC, there was an expansion of the film as the oxidized tails reorientate to associate with the hydrophilic region, consistent with the work by Stachowicz- Ku'snierz et al. Contrarily, the addition of cholesterol leads to a condensation of fluid lipid films, and can buffer the influence of oxidized lipids by incorporating itself into the void created by the truncated tails [93]. This unique behavior of cholesterol to limit oxidative stress is a prime example of the value that molecular dynamics offers to explore the interworking of PS.

\section{Putting It Together}

In summary, the significance of pulmonary surfactant in human physiology has been highlighted within this review. PS can be regarded as one of the most relevant monolayer systems-playing an active role in every breath that keeps us alive. Consequently, research into this system is vitally important, whether it be physical experimentation or in silico simulation. Every investigation on PS bridges the application of biophysical laws to physiological states. Studies thus far begin to describe the biophysical characteristics of the system by isolating and observing the many different interacting components. From lipid composition to the presence of cholesterol, to the role of each individual protein, investigations continue to fuel our understanding of this uniquely complex monolayer system.

One of the most important lipids in the PS system is DPPC, as it is the most abundant of any lipid in the monolayer and is mainly responsible for lowering surface tensions upon compression. The addition of unsaturated lipids complements this behavior by promoting fluidity within the system, while cholesterol tweaks and buffers the order of the monolayer. These variously ordered lipid phases host surfactant proteins, each with a critical role in maintaining the monolayer and its biophysical properties. Together, the convoluted interplay of molecules yields a perfectly balanced system that is rigid, yet responsive enough for the compression and expansion of every breath.

Molecular dynamics has become increasingly popular in the field of biochemistry, owing in part to the flexible, expansive, and informative data offerings. Though powerful, this tool also has its limitations. Although some systems can be represented with similar compositions, the size is not always comparable. Most groups tend toward smaller systems to run simulations more efficiently. For MD simulations, time will always be a factor. Ideally, systems should be run for longer periods of time to confirm larger scale behavior; however, few simulations warrant the computational demand associated with long trajectories. One final limitation with current work is that many case studies focus on a simplified system, choosing the addition of a single component, rather than a full complement. Although valuable for understanding, oversimplification can dilute important contributions from synergistic or antagonistic factors. It is important to be mindful of the weight of simulated studies. It is increasingly evident that molecular simulations provide an unparalleled atomic level of resolution of mimetic pulmonary surfactant systems. As the complexity of these systems increase, a fine line must balance the efficiency of the simulation with attention to detail.

Author Contributions: Resources, M.D. (Maksymilian Dziura) and B.M.; writing-original draft preparation, M.D. (Maksymilian Dziura) and B.M.; writing-review and editing, M.D. (Mitchell DiPasquale), M.D. (Maksymilian Dziura), and D.M.; supervision, P.C.C., J.W.G., and D.M.; project administration, D.M.; funding acquisition, P.C.C., J.W.G., and D.M. All authors have read and agreed to the published version of the manuscript. 
Funding: This work acknowledges support from the Natural Sciences and Engineering Research Council (NSERC) of Canada (funding reference number RGPIN-2018-04841) (Drew Marquardt); the Canadian Institutes for Health Research (CIHR) CGS-D scholarship program (Mitchell DiPasquale) We acknowledge funding support from WE-SPARK Health Institute (and University of Windsor).

Institutional Review Board Statement: Not applicable.

Informed Consent Statement: Not applicable.

Conflicts of Interest: The authors declare no conflict of interest.

\section{References}

1. Martinez-Calle, M.; Prieto, M.; Olmeda, B.; Fedorov, A.; Loura, L.M.S.; Pérez-Gil, J. Pulmonary surfactant protein SP-B nanorings induce the multilamellar organization of surfactant complexes. Biochim. Biophys. Acta (BBA) Biomembr. 2020, $1862,183216$. [CrossRef]

2. Griese, M. Pulmonary surfactant in health and human lung diseases: State of the art. Eur. Respir. J. 1999, 13, 1455-1476. [CrossRef]

3. Agudelo, C.W.; Kumley, B.K.; Area-Gomez, E.; Xu, Y.; Dabo, A.J.; Geraghty, P.; Campos, M.; Foronjy, R.; Garcia-Arcos, I. Decreased surfactant lipids correlate with lung function in chronic obstructive pulmonary disease (COPD). PLoS ONE 2020, 15, e0228279. [CrossRef]

4. Nkadi, P.O.; Merritt, T.A.; Pillers, D.A.M. An overview of pulmonary surfactant in the neonate: Genetics, metabolism, and the role of surfactant in health and disease. Mol. Genet. Metab. 2009, 97, 95-101. [CrossRef]

5. King, R.J. Pulmonary surfactant. J. Appl. Physiol. 1982, 53,1-8. [CrossRef] [PubMed]

6. Weaver, T.E.; Conkright, J.J. Function of surfactant proteins B and C. Annu. Rev. Physiol. 2001, 63, 555-578. [CrossRef] [PubMed]

7. Stahlman, M.T.; Gray, M.P.; Falconieri, M.W.; Whitsett, J.A.; Weaver, T.E. Lamellar body formation in normal and surfactant protein B-deficient fetal mice. Lab. Investig. 2000, 80, 395-403. [CrossRef] [PubMed]

8. Hawgood, S.; Derrick, M.; Poulain, F. Structure and properties of surfactant protein B. Biochim. Biophys. Acta (BBA) Mol. Basis Dis. 1998, 1408, 150-160. [CrossRef]

9. Han, S.; Mallampalli, R.K. The role of surfactant in lung disease and host defense against pulmonary infections. Ann. Am. Thorac. Soc. 2015, 12, 765-774. [CrossRef]

10. Liekkinen, J.; de Santos Moreno, B.; Paananen, R.O.; Vattulainen, I.; Monticelli, L.; De La Serna, J.B.; Javanainen, M. Understanding the Functional Properties of Lipid Heterogeneity in Pulmonary Surfactant Monolayers at the Atomistic Level. Front. Cell Dev. Biol. 2020, 8, 581016. [CrossRef]

11. Perez-Gil, J.; Weaver, T.E. Pulmonary surfactant pathophysiology: Current models and open questions. Physiology 2010, 25, 132-141. [CrossRef]

12. Goerke, J. Pulmonary surfactant: Functions and molecular composition. Biochim. Biophys. Acta (BBA) Mol. Basis Dis. 1998, 1408, 79-89. [CrossRef]

13. Gunasekara, L.; Schürch, S.; Schoel, W.M.; Nag, K.; Leonenko, Z.; Haufs, M.; Amrein, M. Pulmonary surfactant function is abolished by an elevated proportion of cholesterol. Biochim. Biophys. Acta (BBA) Mol. Cell Biol. Lipids 2005, 1737, 27-35. [CrossRef]

14. Brown, A.J.; Galea, A.M. Cholesterol as an evolutionary response to living with oxygen. Evolution 2010, 64, 2179-2183. [CrossRef]

15. Goerke, J.; Gonzales, J. Temperature dependence of dipalmitoyl phosphatidylcholine monolayer stability. J. Appl. Physiol. 1981, 51, 1108-1114. [CrossRef] [PubMed]

16. Veldhuizen, R.; Nag, K.; Orgeig, S.; Possmayer, F. The role of lipids in pulmonary surfactant. Biochim. Biophys. Acta (BBA) Mol. Basis Dis. 1998, 1408, 90-108. [CrossRef]

17. Hidalgo, A.; Cruz, A.; Pérez-Gil, J. Barrier or carrier? Pulmonary surfactant and drug delivery. Eur. J. Pharm. Biopharm. 2015, 95, 117-127. [CrossRef] [PubMed]

18. Hook, G.E.R.; Spalding, J.W.; Ortner, M.J.; Tombropoulos, E.G.; Chignell, C.F. Investigation of phospholipids of the pulmonary extracellular lining by electron paramagnetic resonance. The effects of phosphatidylglycerol and unsaturated phosphatidylcholines on the fluidity of dipalmitoyl phosphatidylcholine. Biochem. J. 1984, 223, 533-542. [CrossRef]

19. Meban, C. Effect of lipids and other substances on the adsorption of dipalmitoyl phosphatidylcholine. Pediatr. Res. 1981, 15, 1029-1031. [CrossRef]

20. Hallman, M.; Enhorning, G.; Possmayer, F. Composition and surface activity of normal and phosphatidylglycerol-deficient lung surfactant. Pediatr. Res. 1985, 19, 286-292. [CrossRef]

21. Baatz, J.E.; Elledge, B.; Whitsett, J.A. Surfactant protein SP-B induces ordering at the surface of model membrane bilayers. Biochemistry 1990, 29, 6714-6720. [CrossRef]

22. Frerking, I.; Günther, A.; Seeger, W.; Pison, U. Pulmonary surfactant: Functions, abnormalities and therapeutic options. Intensive Care Med. 2001, 27, 1699-1717. [CrossRef]

23. Cañadas, O.; Olmeda, B.; Alonso, A.; Pérez-Gil, J. Lipid-protein and protein-protein interactions in the pulmonary surfactant system and their role in lung homeostasis. Int. J. Mol. Sci. 2020, 21, 3708. [CrossRef]

24. Presti, F.T. The role of cholesterol in regulating membrane fluidity. Membr. Fluidity Biol. 1985, 4, 97-145. 
25. Orgeig, S.; Daniels, C.B. The roles of cholesterol in pulmonary surfactant: Insights from comparative and evolutionary studies. Comp. Biochem. Physiol. Part A Mol. Integr. Physiol. 2001, 129, 75-89. [CrossRef]

26. Hadley, N.F. Adaptive Role of Lipids in Biological Systems; Wiley: Hoboken, NJ, USA, 1985.

27. Taneva, S.; Keough, K.M.W. Cholesterol modifies the properties of surface films of dipalmitoylphosphatidylcholine plus pulmonary surfactant-associated protein B or C spread or adsorbed at the air-water interface. Biochemistry 1997, 36, 912-922. [CrossRef]

28. Evans, R.W.; Williams, M.A.; Tinoco, J. Surface viscosities of phospholipids alone and with cholesterol in monolayers at the air-water interface. Lipids 1980, 15, 524-533. [CrossRef]

29. Rubio, S.; Lacaze-Masmonteil, T.; Chailley-Heu, B.; Kahn, A.; Bourbon, J.R.; Ducroc, R. Pulmonary surfactant protein A (SP-A) is expressed by epithelial cells of small and large intestine. J. Biol. Chem. 1995, 270, 12162-12169. [CrossRef] [PubMed]

30. Khubchandani, K.R.; Snyder, J.M. Surfactant protein A (SP-A): The alveolus and beyond. FASEB J. 2001, 15, 59-69. [CrossRef]

31. Guagliardo, R.; Pérez-Gil, J.; De Smedt, S.; Raemdonck, K. Pulmonary surfactant and drug delivery: Focusing on the role of surfactant proteins. J. Control. Release 2018, 291, 116-126. [CrossRef]

32. Cabré, E.J.; Martínez-Calle, M.; Prieto, M.; Fedorov, A.; Olmeda, B.; Loura, L.M.S.; Pérez-Gil, J. Homo-and hetero-oligomerization of hydrophobic pulmonary surfactant proteins SP-B and SP-C in surfactant phospholipid membranes. J. Biol. Chem. 2018, 293, 9399-9411. [CrossRef]

33. Vorbroker, D.K.; Voorhout, W.F.; Weaver, T.E.; Whitsett, J.A. Posttranslational processing of surfactant protein C in rat type II cells. Am. J. Physiol. Lung Cell. Mol. Physiol. 1995, 269, L727-L733. [CrossRef]

34. Mulugeta, S.; Beers, M.F. Surfactant protein C: Its unique properties and emerging immunomodulatory role in the lung. Microbes Infect. 2006, 8, 2317-2323. [CrossRef] [PubMed]

35. Arroyo, R.; Martin-Gonzalez, A.; Echaide, M.; Jain, A.; Brondyk, W.H.; Rosenbaum, J.; Moreno-Herrero, F.; Perez-Gil, J. Supramolecular assembly of human pulmonary surfactant protein SP-D. J. Mol. Biol. 2018, 430, 1495-1509. [CrossRef]

36. Martínez-Calle, M.; Olmeda, B.; Dietl, P.; Frick, M.; Pérez-Gil, J. Pulmonary surfactant protein SP-B promotes exocytosis of lamellar bodies in alveolar type II cells. FASEB J. 2018, 32, 4600-4611. [CrossRef]

37. Taneva, S.G.; Keough, K.M.W. Adsorption of pulmonary surfactant protein SP-A to monolayers of phospholipids containing hydrophobic surfactant protein SP-B or SP-C: Potential differential role for tertiary interaction of lipids, hydrophobic proteins, and SP-A. Biochemistry 2000, 39, 6083-6093. [CrossRef] [PubMed]

38. Bates, S.R.; Dodia, C.; Tao, J.Q.; Fisher, A.B. Surfactant protein-A plays an important role in lung surfactant clearance: Evidence using the surfactant protein-A gene-targeted mouse. Am. J. Physiol. Lung Cell. Mol. Physiol. 2008, 294, L325-L333. [CrossRef]

39. Hiansen, J.Q.; Keating, E.; Aspros, A.; Yao, L.J.; Bosma, K.J.; Yamashita, C.M.; Lewis, J.F.; Veldhuizen, R.A.W. Cholesterolmediated surfactant dysfunction is mitigated by surfactant protein A. Biochim. Biophys. Acta (BBA) Biomembr. 2015, 1848, 813-820. [CrossRef]

40. Liekkinen, J.; Enkavi, G.; Javanainen, M.; Olmeda, B.; Pérez-Gil, J.; Vattulainen, I. Pulmonary Surfactant Lipid Reorganization Induced by the Adsorption of the Oligomeric Surfactant Protein B Complex. J. Mol. Biol. 2020, 432, 3251-3268. [CrossRef]

41. Schürch, D.; Ospina, O.L.; Cruz, A.; Pérez-Gil, J. Combined and independent action of proteins SP-B and SP-C in the surface behavior and mechanical stability of pulmonary surfactant films. Biophys. J. 2010, 99, 3290-3299. [CrossRef]

42. Ingenito, E.P.; Mora, R.; Mark, L. Pivotal role of anionic phospholipids in determining dynamic behavior of lung surfactant. Am. J. Respir. Crit. Care Med. 2000, 161, 831-838. [CrossRef] [PubMed]

43. Ikegami, M.; Na, C.L.; Korfhagen, T.R.; Whitsett, J.A. Surfactant protein D influences surfactant ultrastructure and uptake by alveolar type II cells. Am. J. Physiol. Lung Cell. Mol. Physiol. 2005, 288, L552-L561. [CrossRef]

44. Fukuzawa, T.; Ishida, J.; Kato, A.; Ichinose, T.; Ariestanti, D.M.; Takahashi, T.; Ito, K.; Abe, J.; Suzuki, T.; Wakana, S. Lung surfactant levels are regulated by Ig-Hepta/GPR116 by monitoring surfactant protein D. PLoS ONE 2013, 8, e69451. [CrossRef]

45. Sorensen, G.L. Surfactant protein D in respiratory and non-respiratory diseases. Front. Med. 2018, 5, 18. [CrossRef]

46. Kishore, U.; Greenhough, T.J.; Waters, P.; Shrive, A.K.; Ghai, R.; Kamran, M.F.; Bernal, A.L.; Reid, K.B.M.; Madan, T.; Chakraborty, T. Surfactant proteins SP-A and SP-D: Structure, function and receptors. Mol. Immunol. 2006, 43, 1293-1315. [CrossRef] [PubMed]

47. Sánchez-Barbero, F.; Rivas, G.; Steinhilber, W.; Casals, C. Structural and functional differences among human surfactant proteins SP-A1, SP-A2 and co-expressed SP-A1/SP-A2: Role of supratrimeric oligomerization. Biochem. J. 2007, 406, 479-489. [CrossRef] [PubMed]

48. van de Wetering, J.K.; van Golde, L.M.G.; Batenburg, J.J. Collectins. Eur. J. Biochem. 2004, 271, 1229-1249. [CrossRef]

49. Ikegami, M.; Korfhagen, T.R.; Whitsett, J.A.; Bruno, M.D.; Wert, S.E.; Wada, K.; Jobe, A.H. Characteristics of surfactant from SP-A-deficient mice. Am. J. Physiol. Lung Cell. Mol. Physiol. 1998, 275, L247-L254. [CrossRef]

50. Rice, W.R.; Ross, G.F.; Singleton, F.M.; Dingle, S.; Whitsett, J.A. Surfactant-associated protein inhibits phospholipid secretion from type II cells. J. Appl. Physiol. 1987, 63, 692-698. [CrossRef]

51. Mikerov, A.N.; Umstead, T.M.; Huang, W.; Liu, W.; Phelps, D.S.; Floros, J. SP-A1 and SP-A2 variants differentially enhance association of Pseudomonas aeruginosa with rat alveolar macrophages. Am. J. Physiol. Lung Cell. Mol. Physiol. 2005, 288, L150L158. [CrossRef] [PubMed]

52. Lopez-Rodriguez, E.; Pascual, A.; Arroyo, R.; Floros, J.; Perez-Gil, J. Human pulmonary surfactant protein SP-A1 provides maximal efficiency of lung interfacial films. Biophys. J. 2016, 111, 524-536. [CrossRef]

53. Crouch, E.C. Collectins and pulmonary host defense. Am. J. Respir. Cell Mol. Biol. 1998, 19, 177-201. [CrossRef] 
54. Kuroki, Y.; Voelker, D.R. Pulmonary surfactant proteins. J. Biol. Chem. 1994, 269, 25943-25946. [CrossRef]

55. Barriga, A.; Morán-Lalangui, M.; Castillo-Sánchez, J.C.; Mingarro, I.; Pérez-Gil, J.; García-Álvarez, B. Role of pulmonary surfactant protein Sp-C dimerization on membrane fragmentation: An emergent mechanism involved in lung defense and homeostasis. Biochim. Biophys. Acta (BBA) Biomembr. 2021, 1863, 183572. [CrossRef]

56. Keller, A.; Eistetter, H.R.; Voss, T.; Schäfer, K.P. The pulmonary surfactant protein C (SP-C) precursor is a type II transmembrane protein. Biochem. J. 1991, 277, 493-499. [CrossRef]

57. Melton, K.R.; Nesslein, L.L.; Ikegami, M.; Tichelaar, J.W.; Clark, J.C.; Whitsett, J.A.; Weaver, T.E. SP-B deficiency causes respiratory failure in adult mice. Am. J. Physiol. Lung Cell. Mol. Physiol. 2003, 285, L543-L549. [CrossRef]

58. Qanbar, R.; Cheng, S.; Possmayer, F.; Schurch, S. Role of the palmitoylation of surfactant-associated protein C in surfactant film formation and stability. Am. J. Physiol. Lung Cell. Mol. Physiol. 1996, 271, L572-L580. [CrossRef]

59. Lee, H.; Kandasamy, S.K.; Larson, R.G. Molecular dynamics simulations of the anchoring and tilting of the lung-surfactant peptide SP-B1-25 in palmitic acid monolayers. Biophys. J. 2005, 89, 3807-3821. [CrossRef] [PubMed]

60. Tokieda, K.; Whitsett, J.A.; Clark, J.C.; Weaver, T.E.; Ikeda, K.; McConnell, K.B.; Jobe, A.H.; Ikegami, M.; Iwamoto, H.S. Pulmonary dysfunction in neonatal SP-B-deficient mice. Am. J. Physiol. Lung Cell. Mol. Physiol. 1997, 273, L875-L882. [CrossRef]

61. Glasser, S.W.; Burhans, M.S.; Korfhagen, T.R.; Na, C.L.; Sly, P.D.; Ross, G.F.; Ikegami, M.; Whitsett, J.A. Altered stability of pulmonary surfactant in SP-C-deficient mice. Proc. Natl. Acad. Sci. USA 2001, 98, 6366-6371. [CrossRef]

62. Creuwels, L.; Van Golde, L.M.G.; Haagsman, H.P. The pulmonary surfactant system: Biochemical and clinical aspects. Lung 1997, 175, 1-39. [CrossRef]

63. Zuo, Y.Y.; Veldhuizen, R.A.W.; Neumann, A.W.; Petersen, N.O.; Possmayer, F. Current perspectives in pulmonary surfactantInhibition, enhancement and evaluation. Biochim. Biophys. Acta (BBA) Biomembr. 2008, 1778, 1947-1977. [CrossRef]

64. Rodríguez-Capote, K.; Manzanares, D.; Haines, T.; Possmayer, F. Reactive oxygen species inactivation of surfactant involves structural and functional alterations to surfactant proteins SP-B and SP-C. Biophys. J. 2006, 90, 2808-2821. [CrossRef] [PubMed]

65. Sabatini, K.; Mattila, J.P.; Megli, F.M.; Kinnunen, P.K.J. Characterization of two oxidatively modified phospholipids in mixed monolayers with DPPC. Biophys. J. 2006, 90, 4488-4499. [CrossRef]

66. Stachowicz-Kuśnierz, A.; Cwiklik, L.; Korchowiec, J.; Rogalska, E.; Korchowiec, B. The impact of lipid oxidation on the functioning of a lung surfactant model. Phys. Chem. Chem. Phys. 2018, 20, 24968-24978. [CrossRef] [PubMed]

67. Possmayer, F.; Nag, K.; Rodriguez, K.; Qanbar, R.; Schürch, S. Surface activity in vitro: Role of surfactant proteins. Comp. Biochem. Physiol. Part A Mol. Integr. Physiol. 2001, 129, 209-220. [CrossRef]

68. Ding, J.; Takamoto, D.Y.; Von Nahmen, A.; Lipp, M.M.; Lee, K.Y.C.; Waring, A.J.; Zasadzinski, J.A. Effects of lung surfactant proteins, SP-B and SP-C, and palmitic acid on monolayer stability. Biophys. J. 2001, 80, 2262-2272. [CrossRef]

69. Diemel, R.V.; Snel, M.M.E.; Waring, A.J.; Walther, F.J.; van Golde, L.M.G.; Putz, G.; Haagsman, H.P.; Batenburg, J.J. Multilayer formation upon compression of surfactant monolayers depends on protein concentration as well as lipid composition: An atomic force microscopy study. J. Biol. Chem. 2002, 277, 21179-21188. [CrossRef]

70. Rugonyi, S.; Biswas, S.C.; Hall, S.B. The biophysical function of pulmonary surfactant. Respir. Physiol. Neurobiol. 2008, 163, 244-255. [CrossRef]

71. Parra, E.; Pérez-Gil, J. Composition, structure and mechanical properties define performance of pulmonary surfactant membranes and films. Chem. Phys. Lipids 2015, 185, 153-175. [CrossRef]

72. Zuo, Y.Y.; Possmayer, F. How does pulmonary surfactant reduce surface tension to very low values? J. Appl. Physiol. 2007, 102, 1733-1734. [CrossRef]

73. Hansson, T.; Oostenbrink, C.; van Gunsteren, W. Molecular dynamics simulations. Curr. Opin. Struct. Biol. 2002, 12, 190-196. [CrossRef]

74. Agrahari, A.K.; Pieroni, E.; Gatto, G.; Kumar, A. The impact of missense mutation in PIGA associated to paroxysmal nocturnal hemoglobinuria and multiple congenital anomalies-hypotonia-seizures syndrome 2: A computational study. Heliyon 2019, 5, e02709. [CrossRef]

75. Kumar, A.; Sechi, L.A.; Caboni, P.; Marrosu, M.G.; Atzori, L.; Pieroni, E. Dynamical insights into the differential characteristics of Mycobacterium avium subsp. paratuberculosis peptide binding to HLA-DRB1 proteins associated with multiple sclerosis. New J. Chem. 2015, 39, 1355-1366. [CrossRef]

76. Pal, R.; Kumar, A.; Misra, G. Exploring TEAD2 as a drug target for therapeutic intervention of cancer: A multi-computational case study. Brief. Bioinform. 2021. [CrossRef]

77. Ammarah, U.; Kumar, A.; Pal, R.; Bal, N.C.; Misra, G. Identification of new inhibitors against human Great wall kinase using in silico approaches. Sci. Rep. 2018, 8, 1-12. [CrossRef]

78. May, A.; Pool, R.; van Dijk, E.; Bijlard, J.; Abeln, S.; Heringa, J.; Feenstra, K.A. Coarse-grained versus atomistic simulations: Realistic interaction free energies for real proteins. Bioinformatics 2014, 30, 326-334. [CrossRef]

79. Rose, D.; Rendell, J.; Lee, D.; Nag, K.; Booth, V. Molecular dynamics simulations of lung surfactant lipid monolayers. Biophys. Chem. 2008, 138, 67-77. [CrossRef]

80. Duncan, S.L.; Dalal, I.S.; Larson, R.G. Molecular dynamics simulation of phase transitions in model lung surfactant monolayers. Biochim. Biophys. Acta (BBA) Biomembr. 2011, 1808, 2450-2465. [CrossRef]

81. Baoukina, S.; Tieleman, D.P. Computer simulations of lung surfactant. Biochim. Biophys. Acta (BBA) Biomembr. 2016, 1858, 24312440. [CrossRef] 
82. Pocivavsek, L.; Dellsy, R.; Kern, A.; Johnson, S.; Lin, B.; Lee, K.Y.C.; Cerda, E. Stress and fold localization in thin elastic membranes. Science 2008, 320, 912-916. [CrossRef]

83. Baoukina, S.; Monticelli, L.; Amrein, M.; Tieleman, D.P. The molecular mechanism of monolayer-bilayer transformations of lung surfactant from molecular dynamics simulations. Biophys. J. 2007, 93, 3775-3782. [CrossRef]

84. Baoukina, S.; Rozmanov, D.; Mendez-Villuendas, E.; Tieleman, D.P. The mechanism of collapse of heterogeneous lipid monolayers Biophys. J. 2014, 107, 1136-1145. [CrossRef]

85. Johansson, J.; Curstedt, T. Molecular structures and interactions of pulmonary surfactant components. Eur. J. Biochem. 1997, 244, 675-693. [CrossRef]

86. Lee, K.Y.C.; Lipp, M.M.; Zasadzinski, J.A.; Waring, A.J. Effects of lung surfactant specific protein SP-B and model SP-B peptide on lipid monolayers at the air-water interface. Colloids Surf. A Physicochem. Eng. Asp. 1997, 128, 225-242. [CrossRef]

87. Krüger, P.; Schalke, M.; Wang, Z.; Notter, R.H.; Dluhy, R.A.; Lösche, M. Effect of hydrophobic surfactant peptides SP-B and SP-C on binary phospholipid monolayers. I. Fluorescence and dark-field microscopy. Biophys. J. 1999, 77, 903-914. [CrossRef]

88. Freites, J.A.; Choi, Y.; Tobias, D.J. Molecular dynamics simulations of a pulmonary surfactant protein B peptide in a lipid monolayer. Biophys. J. 2003, 84, 2169-2180. [CrossRef]

89. Goh, B.C.; Rynkiewicz, M.J.; Cafarella, T.R.; White, M.R.; Hartshorn, K.L.; Allen, K.; Crouch, E.C.; Calin, O.; Seeberger, P.H.; Schulten, K. Molecular mechanisms of inhibition of influenza by surfactant protein D revealed by large-scale molecular dynamics simulation. Biochemistry 2013, 52, 8527-8538. [CrossRef]

90. Chen, P.; Zhang, Z.; Gu, N.; Ji, M. Effect of the surface charge density of nanoparticles on their translocation across pulmonary surfactant monolayer: A molecular dynamics simulation. Mol. Simul. 2018, 44, 85-93. [CrossRef]

91. Bakshi, M.S.; Zhao, L.; Smith, R.; Possmayer, F.; Petersen, N.O. Metal nanoparticle pollutants interfere with pulmonary surfactant function in vitro. Biophys. J. 2008, 94, 855-868. [CrossRef]

92. Yue, K.; Sun, X.; Tang, J.; Wei, Y.; Zhang, X. A Simulation Study on the Interaction Between Pollutant Nanoparticles and the Pulmonary Surfactant Monolayer. Int. J. Mol. Sci. 2019, 20, 3281. [CrossRef] [PubMed]

93. Olzyńska, A.; Delcroix, P.; Dolejšová, T.; Krzaczek, K.; Korchowiec, B.; Czogalla, A.; Cwiklik, L. Properties of lipid models of lung surfactant containing cholesterol and oxidized lipids: A mixed experimental and computational study. Langmuir 2020, 36, 1023-1033. [CrossRef] [PubMed] 